www.jmscr.igmpublication.org

Impact Factor (SJIF): 5.84

Index Copernicus Value: 71.58

ISSN (e)-2347-176x ISSN (p) 2455-0450

crossref DOI: _https://dx.doi.org/10.18535/jmscr/v6i1.186

Journal Of Medical Science And Clinical Research

\title{
Pattern of Acute Kidney Injury in Tropical Febrile Illness - A Retrospective Clinical Study
}

\author{
Authors \\ Dr Padmakumar R Pillai ${ }^{1}$, Dr Regi David Sam ${ }^{2 *}$ \\ *Corresponding Author \\ Dr Regi David Sam \\ Email: regidavid1981@gmail.com
}

${ }^{1}$ Associate Professor, Department of Internal Medicine, Govt Medical College, Thiruvananthapuram, Kerala

${ }^{2}$ Assistant Professor, Department of Internal Medicine, Govt. Medical College, Thiruvananthapuram, Kerala

\section{Introduction}

Rapid decline in the glomerular filtration rate (GFR) within a period of hours to weeks with resultant retention of nitrogenous waste products such as blood urea nitrogen (BUN) and creatinine is characteristic of acute kidney injury.

Identification of acutely impaired kidney function, typically is based on a change in serum creatinine and/or urine output. Risk, Injury, Failure, Loss of kidney function, and End-stage kidney disease was accepted as the definition of AKI in 2004 according to consensus and is effectively described by the acronym RIFLE. Recent studies have shown that the stages or levels of AKI defined by the RIFLE criteria are predictive of increased risk of mortality and dialysis dependent kidney failure in critically ill patients.

The RIFLE classification effectively categorizes AKI in the clinical setting and can be used in different populations. It is also a good prognostic indicator in AKI. Increased mortality is noted in patients with worse RIFLE class. The RIFLE criteria was later modified and referred to as the acute kidney injury network (AKIN) definition.
Compared with the RIFLE classification, the AKIN definition includes lesser degrees of serum creatinine elevation to diagnose AKI, identical grades of oliguria, and a similar severity staging system.

AKI is defined ${ }^{29}$ as any of the following:

- Increase in S. Cr by more than $0.3 \mathrm{mg} / \mathrm{dl}$ within 48 hours; or

- Increase in S. Cr to x1.5 times baseline, within 7 days; or

- Reduction in urine volume less than 0.5 $\mathrm{ml} / \mathrm{kg} / \mathrm{h}$ for 6 hours.

Infections are responsible for about $50 \%$ of cases with acute kidney injury (AKI) in the tropics. A wide variety of tropical infections are known to cause acute kidney injury. Many pathogens directly infect renal parenchyma inducing immune response and AKI. Systemic inflammatory response secondary to tropical infections also cause hemodynamic alterations and resultant AKI. The severity of AKI is influenced by genetic, environmental and socioeconomic factors apart from the virulence of the pathogen and nature of immune response. The clinical features by which 
patients with tropical AKI present vary widely. Malnutrition, pre-existing morbidities, haemolysis, rhabdomyolysis, multiorgan affection and disseminated intravascular coagulation influence the clinical syndrome.

\section{Objectives of the Study}

1. Clinical profile of patients admitted with acute febrile illness with acute kidney injury in medical wards.

2. Clinical and biochemical factors that determine outcome.

\section{Materials and Methods \\ Study Subjects}

This retrospective clinical study was carried out reviewing the case files of patients $>/=15 \mathrm{yrs}$ with acute febrile illness of duration less than 1 week and fulfilling the definition criteria for acute kidney injury (AKIN criteria) admitted under internal medicine department of our institution . The case files of 450 patients admitted between January 2015 and July 2018 were reviewed.

\section{Exclusion Criteria}

History of Chronic Kidney Disease

Long Time Analgesic Use

Diabetic Nephropathy.

Hypertension.

\section{Methodology}

Case files of 450 patients who fulfilled the inclusion criteria were included in the study.

\section{Methods}

In this retrospective clinical study, case files of 450 patients $>/=15$ yrs who presented with fever of less than 1 week duration and fulfilled the definition criteria for acute kidney injury by AKIN were selected. Note was made of clinical manifestations and serological test results of the selected patients. Acute febrile illness of the study population included dengue fever, leptospirosis, scrub typhus, typhoid fever and malaria which are prevalent in this area.

\section{Data Analysis}

The Statistical software, SPSS 17.0 was used for the analysis of the data. The differences in characteristics were using chi-squire test or student's t-test. The significant association was determined by a $\mathbf{p}$ value of less than or equal to 0.05 .

\section{Ethical Consideration}

The data collection for the study was started only after getting the clearance from the ethical committee.

\section{Observations and Results}

Table No.1: Percentage distribution of the sample according to age

\begin{tabular}{|l|c|c|}
\hline Age & Frequency & Percent \\
\hline$<25$ & 30 & 6.7 \\
\hline $25-34$ & 72 & 16.0 \\
\hline $35-44$ & 75 & 16.7 \\
\hline $45-54$ & 123 & 27.3 \\
\hline $55-64$ & 104 & 22.7 \\
\hline $65-74$ & 39 & 8.7 \\
\hline $75-84$ & 9 & 2.0 \\
\hline Total & 450 & 100.0 \\
\hline
\end{tabular}

Fig .No.1: Percentage distribution of the sample according to age

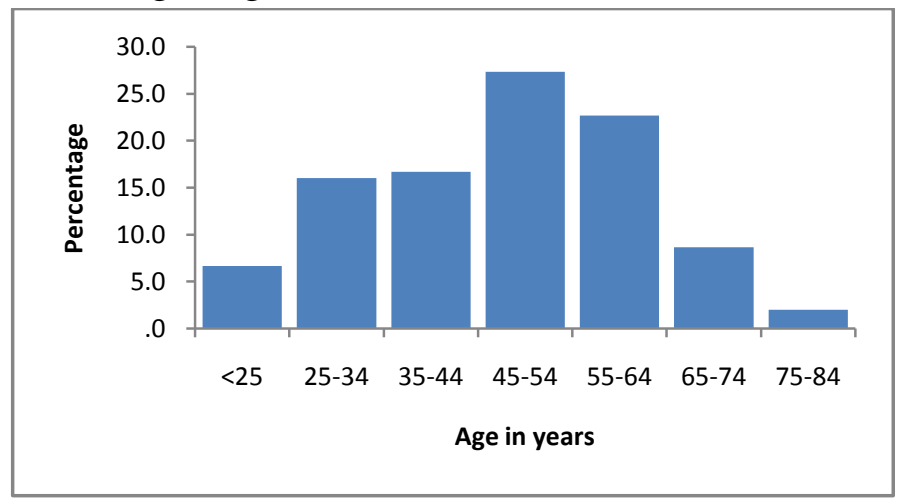

Maximum number of cases were seen in the age group between 45-54yr [27.3\%.].

Table No.2: Percentage distribution of the sample according to sex

\begin{tabular}{|l|c|c|}
\hline Gender & Frequency & Percent \\
\hline Male & 300 & 67 \\
\hline Female & 150 & 33 \\
\hline Total & 450 & 100.0 \\
\hline
\end{tabular}




\section{JMSCR Vol||06||Issue||01||Page 32582-32587||January}

Fig No.2: Percentage distribution of the sample according to sex

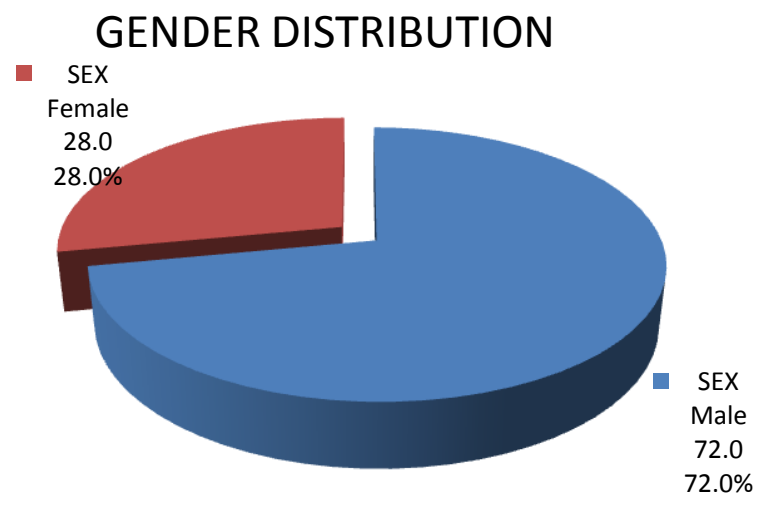

Majority of patients were males (72\%)

Table No.3: Percentage distribution of the sample according to presence of oliguria

\begin{tabular}{|l|c|c|}
\hline Oliguria & Frequency & Percent \\
\hline Present & $\mathbf{3 0 0}$ & $\mathbf{6 7}$ \\
\hline Absent & $\mathbf{1 5 0}$ & $\mathbf{3 3}$ \\
\hline
\end{tabular}

Fig. No.3: Percentage distribution of the sample according to presence of oliguria

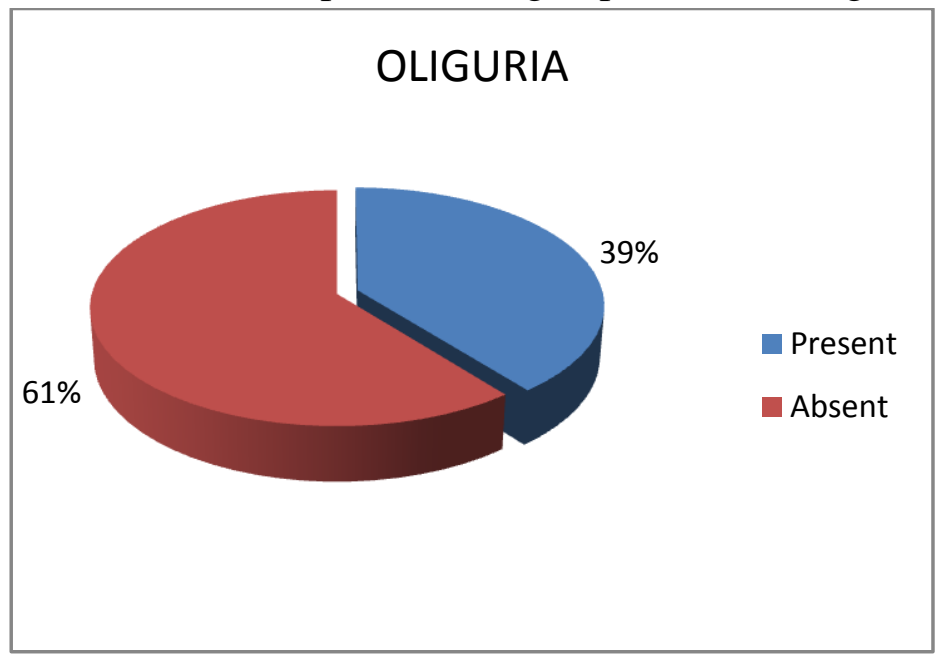

$39 \%$ patients had decreased urine output at presentation

Table No.4: Percentage distribution of the sample according to diseases

\begin{tabular}{|l|c|}
\hline Diseases & Frequency \\
\hline SCRUB TYPHUS & 80 \\
\hline LEPTOSPIROSIS & 290 \\
\hline DENGUE & 56 \\
\hline MALARIA & 4 \\
\hline TYPHOID & 0 \\
\hline UNDIFFERENTIATED & 20 \\
\hline
\end{tabular}


Fig. No.4: Percentage distribution of the sample according to diseases

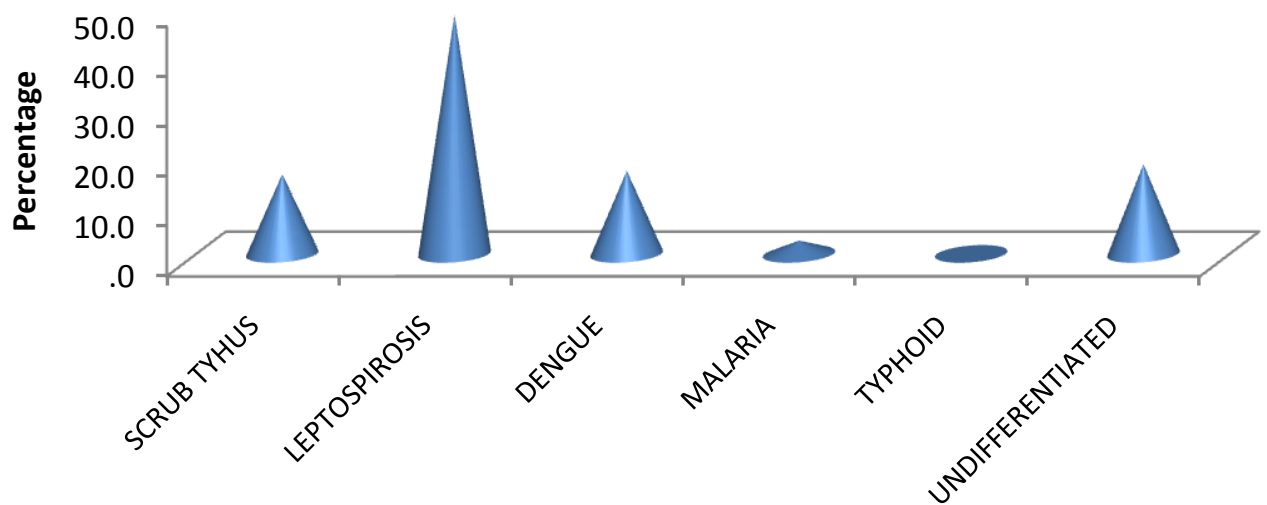

Of the 450 cases, $72(48 \%)$ were diagnosed as Leptospirosis, 25(16.7\%) were Dengue, 24(16\%) were Scrub typhus, $4(2.7 \%)$ were tested positive for malaria and the rest 27(18\%) were included in the category of undifferentiated acute febrile illness.

Table No.5: Mean of various quantitative variables

\begin{tabular}{|l|c|c|c|c|}
\hline variables & Minimum & Maximum & Mean & $\begin{array}{c}\text { Std. } \\
\text { Deviation }\end{array}$ \\
\hline Age & 15 & 75 & 42.7 & 13.8 \\
\hline Duration of fever & 2 & 9 & 4.5 & 3.2 \\
\hline Blood pressure & $90 / 60$ & $160 / 90$ & 110 & 1.8 \\
\hline Haemoglobin. & 8 & 15 & 10 & 1.2 \\
\hline Heart rate & 60 & 130 & 100 & 5.4 \\
\hline Platelet & 5000 & 45000 & 60705.3 & 64955.7 \\
\hline ESR & 11 & 112 & 47.9 & 34.6 \\
\hline S. Bilirubin & .8 & 23 & 4.0 & 4.1 \\
\hline SGOT & 26 & 3822 & 115.3 & 352.9 \\
\hline SGPT & 33 & 2141 & 147.1 & 212.3 \\
\hline ALP & 61 & 594 & 161.4 & 87.8 \\
\hline Blood Urea & 18 & 210 & 71.7 & 51.0 \\
\hline S. Creatinine & 0.8 & 8 & 3.9 & 1.9 \\
\hline
\end{tabular}

\section{Discussion}

In this study out of 450 cases, maximum number of cases were seen in the age group between 45$54 \mathrm{yrs}-27.3 \%$. Mean age was $46.7 \pm 13.8$. $72 \%$ were males and $28 \%$ were females. $72(48 \%)$ were diagnosed as Leptospirosis, 25(16.7\%) were Dengue fever, 24(16\%) were Scrub typhus, $4(2.7 \%)$ were tested positive for malaria and the rest $27(18 \%)$ were included in the category of undifferentiated acute febrile illness. According to the study conducted by Gopal Basu et al. $^{2}$ at Christian Medical College, Vellore on tropical acute febrile illness, mean age at diagnosis was $39.7 \pm 16.9$ years and $60 \%$ were males. Scrub typhus $(51.2 \%)$, falciparum malaria $(10.4 \%)$, enteric fever $(8.7 \%)$, dengue $(7.6 \%)$, mixed malaria $(6.5 \%)$, leptospirosis $(3.3 \%)$, undifferentiated acute febrile illness $(8.4 \%)$ constituted the cases. Leptospirosis, Scrub typhus and dengue fever were major causes of AKI in this study.

In this study, $62 \%$ patients had icterus at presentation. Icterus was found to be associated with higher stages of acute kidney injury $(\mathrm{p}=0.000)$ but had no significant relation to outcome $(\mathrm{p}=0.088)$. This is in accordance to the study conducted by Dassanayake et al. ${ }^{17}$ on patients with leptospirosis in which oliguria and jaundice were predictors of acute renal failure.

In this study, 39\% patients had decreased urine output at presentation., according to Brivet FG et 
al. ${ }^{9}$ who studied the prognostic factors and the outcome of patients with severe acute renal failure concluded that presence of oliguria was a strong predictor of mortality

In this study, $12.7 \%$ patients had hypotension at presentation.

In this study $12.7 \%$ patients had altered sensorium at presentation. This finding is in accordance with Ko AI et al. ${ }^{14}$ who conducted a study on urban epidemic of leptospirosis concluded that altered mental status was the strongest independent predictor of death.

In this study $61 \%$ patients had tachycardia at presentation and $41 \%$ patients had tachypnea at presentation. In a study conducted by Metcalfe et al. ${ }^{10}$, an increase in heart rate was found to be significantly associated with hospital death.

In this study out of the 150 cases, $118(78.7 \%)$ patients had full recovery while 32 (21.3\%) patients died during hospital stay.In this study, 42.7\% patients were alcoholics. Alcoholism was associated with higher serum creatinine. High Total count, lower haemoglobin and high baseline serum creatinine were significantly associated with death.

\section{Conclusions}

- Leptospirosis (48\%), Dengue (16.7\%), Scrub typhus (16\%), Malaria (2.7\%) were the major tropical febrile illness causing acute kidney injury.

- Mortality was $21.3 \%$ during hospital stay.

- Presence of oliguria, tachycardia, tachypnoea, hypotension and altered sensorium at admission were found to be significantly associated with higher stages of acute kidney injury and mortality.

- Presence of icterus at admission and history of alcoholism were found to be significantly associated with higher stages of acute kidney injury but had no significant relation to outcome.

- Leptospirosis produced severe forms of acute kidney injury while dengue and scrub typhus produced relatively milder forms of acute kidney injury

\section{Bibliography}

1. Uchino S, Kellum JA, Bellomo R, Doig GS, Morimatsu H, Morgera S, Schetz M, Tan I, Bouman C, Macedo E, Gibney N, Tolwani A, Ronco C; Beginning and Ending Supportive Therapy for the Kidney (BEST Kidney) Investigators. JAMA. 2005 Aug 17; 294(7):813-8.

2. Basu G, Chrispal A, Boorugu H, Gopinath KG, Chandy S, Prakash JA, Thomas K, Abraham AM, John GT. Acute kidney injury in tropical acute febrile illness in a tertiary care centre-RIFLE criteria validation. Nephrol Dial Transplant. 2011 Feb; 26(2):524-31. Epub 2010 Aug 11.

3. KS Mehta, AR Halankar, PD Makwana, PP Torane, PS Satija, VB Shah et al. Severe acute renal failure in Malaria, TN medical college, Mumbai. JPGM. Year : 2001 | Vol: 47 | Issue : 1 | Page : 24-27.

4. Khosla SN, Lochan $\mathrm{R}$ et al. Acute renal dysfunction in enteric fever. $\mathrm{J}$ Assoc Physicians India. 1992 Feb; 40(2):137-

5. Brivet FG, Kleinknecht DJ, Loirat $P$, Landais PJ: Acute renal failure in intensive care units-causes, outcome, and prognostic factors of hospital mortality: A prospective, multicenter study. French Study Group on Acute Renal Failure. Crit Care Med24 :192- 198,1

6. Mehta RL, Pascual MT, Gruta CG, Zhuang S, Chertow GM: Refining predictive models in critically ill patients with acute renal failure. $\mathbf{J}$ Am Soc Nephrol13:1350- 1357, 2002.

7. Mehra N, Patel A, Abraham G, Reddy YN, Reddy YN. Acute kidney injury in dengue fever using Acute Kidney Injury Network criteria: incidence and risk factors. Trop Doct. 2012 Jul; 42(3):160-2.Epub 2012 Ap

8. Ko AI, Galvão Reis M, Ribeiro Dourado CM, Johnson WD Jr, Riley LW. Urban 
epidemic of severe leptospirosis in Brazil.

Salvador Leptospirosis Study Group. Lancet. 1999 Sep 4; 354(9181):820-5

9. Dassanayake DL, Wimalaratna $\mathrm{H}$, Nandadewa D, Nugaliyadda A, Ratnatunga $\mathrm{CN}$, Agampodi SB. Predictors of the development of myocarditis or acute renal failure in patients with leptospirosis: an observational study. BMC Infect Dis. 2012 Jan $13 ; 12$.

10. Kaul A, Sharma RK, Tripathi R, Suresh KJ, Bhatt S, Prasad N. Spectrum of community-acquired acute kidney injury in India: a retrospective study. Saudi J Kidney Dis Transpl. 2012 May;23(3):6192. 